\title{
Dispersion of hazardous nanoparticles on beaches around phosphogypsum factories
}

doi: https://doi.org/10.1016/j.marpolbul.2021.112493

url: https://www.sciencedirect.com/science/article/abs/pii/S0025326X21005270

\section{Authors}

Luis F.O. Silva, Diana Pinto, Marcos L.S. Oliveira, Guilherme L. Dotto

\begin{abstract}
Anthropogenic occurring nanoparticles (NPs) have been one of the principal catalytic components of marine pollution throughout its history. The phosphogypsum (PG) factories present environmental risks and evident marine pollution in different parts of the world. Many of these factors continue to operate, however, some have already been abandoned by the private sector. The general objective of this manuscript is to analyze the real nanoparticles (NPs) present on a beach in southern Brazil to illustrate the need to create public policies and projects for environmental recovery. This work focused on real representative sampling of suspended sediments (SSs), and on a modern analytical procedure via advanced electron microscopes (field emission scanning electron microscope-FE-SEM and high resolution transmission electron microscope-HR-TEM coupled with an energy dispersive X-ray microanalysis system-EDS) to analyze NPs containing hazardous elements (HEs). The results presented in this work demonstrate who the size, morphology, among other physical-geochemical characteristics influence in the adsorption of HEs by the NPs and their respective agglomerates. This study is of great importance for carrying out the application of advanced techniques and methods to better understand the formation and transport of NPs on beaches, which allows assisting in the management of waste from plaster factories on a global scale.
\end{abstract}

\section{Keywords}

Nanoparticles, Impacted beaches, Hazardous elements, Phosphogypsum, Abandoned industry 